\title{
A pilot study utilising cross-age peer tutoring as a method of intervention for anxious adolescents
}

\author{
Dr Marilyn Campbell \\ School of Learning and Professional Studies \\ Queensland University of Technology \\ Brisbane, Australia
}

\begin{abstract}
Anxiety disorders are the most common psychopathology experienced by young people, with up to $18 \%$ of adolescents developing one. The consequences of these symptoms, if left untreated, include impaired peer relationships, school absenteeism and self-concept problems. In addition, excessive anxiety may play a causal role in the development of depression in young people, precede eating disorders and predispose adolescents to substance abuse disorders.

While the school is often chosen as a place to provide early intervention for these debilitating symptoms, identifying sufferers is difficult because excessive anxiety is often not recognised in school and young people are reluctant to seek help. Even when these young people are identified, there are problems in providing sensitive programs that do not stigmatise them within a school setting. One method that may engage this adolescent population is cross-age peer tutoring.

This paper reports on a small pilot study using the Worrybusters program and a cross-age peer tutoring method to engage anxious adolescents. Secondary school students with anxiety were invited to plan activities for primary school students who had been referred by a teacher as also suffering from anxiety. The secondary students prepared the activities across the course of a term in the high school setting, and then delivered them to the younger students in weekly sessions at the primary school during the following term. Although the secondary school students decreased their scores on anxiety self-report measures, there were no significant differences in primary school students' self-reports. However, reports from the primary
\end{abstract}


school students' parents indicated a significant decrease in their children's anxiety.

\section{Introduction}

Adolescent mental health issues have been shown to be an important public health problem in Australian epidemiological studies in the last decade (Sawyer et al. 2000). Many of these disorders - such as anxiety, depression, substance abuse and psychosis - have their peak period of onset during this time (Davis et al. 2000). Anxiety disorders in particular are the most prevalent type of disorder experienced by young people (Albano, Chorptia \& Barlow 1996; Barrett \& Turner 2001; Verhulst et al. 1997), with up to $18 \%$ of adolescents developing one (Costello \& Angold 1995; Kashani \& Orvashcek 1990). Not only do many adolescents have comorbid conditions with anxiety, but it has been proposed (Dobson 1985) that anxiety and depression lie on a developmental continuum and that anxiety predates many of these other disorders.

Recent evidence suggests that childhood anxiety may play a causal role in the development of depression among young people (Cole et al. 1998), and anxiety has been shown to precede the eating disorder in most cases (Godart et al. 2000). There is also preliminary evidence to suggest that anxiety may predispose adolescents to develop substance-use disorders (Burke, Burke \& Rae 1994; Deas-Nesmith, Brady \& Campbell 1998; Rodhe, Lewinsohn \& Selby 1996), and that there is an increasing risk of suicide as a consequence of anxiety (Mattison 1988).

Students with excessive anxiety have been shown to have lower academic achievement (Ialongo et al. 1994; Ialongo et al. 1995), more peer relationship problems (Strauss, Frame \& Forehand 1987) and impairments in general social competence (Messer \& Beidel 1994). Excessive school absenteeism and impaired peer relationships associated with anxiety lead to poor vocational adjustment (Hibbert, Fogelman \& Manor 1990) and self-concept problems (Asher \& Coie 1990), as well as psychiatric disorders later in life (Kovacs \& Devlin 1998).

Adolescence is a 'window of opportunity' for intervening in mental health disorders (Martin \& Cohen 2000). During adolescence young people develop the ability to reflect on their inner distress, which makes this time crucial for early identification and involvement in intervention programs (Reinherz et al. 2003). The school is generally the place chosen for mental health promotion, prevention and early intervention efforts, as this is where students are easily accessible and spend half their waking hours (McBride, Midford \& James 1995). Schools have the potential to offer interventions that address mental health problems from a developmental ecological perspective (Barnes 1998), thus preventing escalation of difficulties for those students experiencing problems. Whilst the school can be the base for intervention programs, difficulties exist in identifying and then engaging those adolescents who are highly anxious.

Many mental health symptoms, especially those associated with anxiety and depression, are difficult to recognise in adolescents due to the internalising nature of the disorders. Teachers are not adept at recognising adolescents who are excessively 
anxious, and thus such students tend to be under-identified and under-referred (Abidin \& Robinson 2002; Gardiner 1994; Green, Clopton \& Pope 1996; Pearcy, Clopton \& Pope 1993). An interesting finding by Pearcy, Clopton and Pope (1993) was that teacher referral increased as the severity of the student's externalising problems increased, but decreased as the internalising problems of the students became more severe. In addition, teachers in secondary schools spend substantially less time with students than primary school teachers do, and so have limited time to observe and interact with them (Cantwell et al. 1997). Further, school routine often enables excessively anxious students to hide their symptoms, so that adults are often unaware of their problems (Donovan \& Spence 2000).

Compounding this problem is that anxious adolescents tend not to seek help themselves. There is a stigma in help-seeking behaviour in general in Australia (Jorm 2000), and this is thought to be even stronger for adolescents (Frydenberg \& Lewis 2000). Rickwood (1995) found approximately half of a sample of Australian secondary school students did not ask for help with their 'psychological' problems. Unfortunately, the percentage of youth in the non-clinical population who are unwilling to seek help increases as mental health problems increase (Carlton \& Deane 2000; Deane, Wilson \& Ciarrochi 2001). Adolescents who are poor at identifying, describing and managing their emotions (emotional competence) have the lowest intentions to seek help (Ciarrochi et al. 2003); while Wilson and Deane (2001) suggest that the cognitive distortions accompanying excessive anxiety (such as rumination and overgeneralisation) might in fact act as added barriers to appropriate help-seeking.

Effective diagnosis now relies on multiple informants and methods (Kazdin \& Weisz 1998; Kraemer et al. 2003). Therefore, it would seem that a tripartite model of identification of at-risk students by teacher referral, support staff referral and self-report screening could be most beneficial in identifying adolescents for a range of interventions in the secondary school (Campbell 2004). Even when anxious adolescents are identified using this tripartite model, there remains the difficulty of providing intervention programs in school that engage students in a sensitive way, without stigmatising them. School-based early intervention programs can reduce anxiety symptoms in some children (e.g. Dadds et al. 1999; Miller 2008; Tomb \& Hunter 2004). However, with programs that are used as selective interventions, such as FRIENDS (Farrell, Barrett \& Claassens 2005), there is a potential to stigmatise adolescents and there can be difficulties with engaging them. Cross-age peer tutoring could be one way to engage anxious adolescents in the school setting, where such students would usually be reluctant to participate in treatment programs.

Cross-age peer tutoring in general terms involves older students helping younger students to learn new skills or concepts (Jacobson et al. 2001). Successful programs pair such diverse age groupings as: university with primary school students (Juel 1991); high school with primary students (McKinstery \& Topping 2003; Ellis et al. 2003); and upper primary with lower primary students (Gensemer 2000). Older students serve as role models with first-hand experience of what is confronting their young tutees (Gaustad 1993). Gaustad (1993) suggests that tutors, being students themselves, are cognitively closer to their tutees than adult teachers 
and counsellors. They are better, therefore, at understanding tutees' non-verbal behaviour and are thus able to present concepts in ways more readily understood by tutees. Consequently, tutor and tutee are able to establish strong bonds that cannot be realised with the usual teacher-student relationship, and which can assist younger students in their learning (Gaustad 1993). According to Nugent (2001), the relationship appears to benefit both tutor and tutee in an academic, social and affective sense. These mutual benefits are one of the major strengths of cross-age tutoring.

Students selected to be tutors need not necessarily be the highest achievers academically. Nugent (2001) found that students with mild learning difficulties were able to successfully tutor younger students who also had learning difficulties. Gains for tutors have been consistently repeated across studies, including: improvements in communication skills, self-esteem and organisational skills (Noll 1997); acceptance of greater responsibilities and increased independence in class (Gensemer 2000); cognitive gains; and the development of personal leadership skills (Potter 1997).

Writers such as Noll (1997) and Miller and Miller (1995), who have conducted studies on cross-age peer tutoring, have also examined programs for nonacademic skills. Noll (1997) implemented a program for developing social skills, involving ninth-grade volunteers tutoring seventh-grade students with learning disabilities, and found that the students with a learning disability made significant gains in social development. Miller and Miller's (1995) study focused on promoting self-determination in students who had severe emotional or behavioural disorders, with an emphasis on developing problem-solving skills, self-assertiveness and selfmanagement. Cross-age peer tutoring was found to be an effective service delivery strategy in promoting self-determination in these students. In addition, in a study of the effects of cross-age peer tutoring on students' self-concept, Ellis et al. (2003) found that students reported a greater capacity to cope with change and seek social support when faced with difficulties. The students also exhibited a reduction in their acceptance of bullying behaviour. The success of these cross-age peer tutoring programs suggests that there is scope for further exploration in the non-academic realm.

One such area that needs to be further explored is how to address the needs of students who are excessively anxious. To date, there has been no research identified that has examined cross-age peer tutoring in relation to assisting students with anxiety issues. The following small pilot study used the Worrybusters program (developed by the author for primary school children with anxiety symptoms) in a cross-age peer tutoring mode, with one group of anxious students from a secondary school tutoring a group of anxious students from a primary school. It was expected that there would be a reported reduction of anxiety in both groups of students after completion of the program. It was also anticipated that both groups of students would engage with and enjoy the program, and that the program would be acceptable to school staff. 


\section{Methodology}

\section{Participants}

Seven students ( 4 boys and 3 girls) in Year 9 from a large city secondary school in Brisbane and nine students ( 8 boys and 1 girl) in Years $1-4$ from the nearby primary school were recruited for the study. The high school students were identified as anxious using a multi-modal method of teacher referral, support staff identification and student self-report as part of the school's regular identification of students with high support needs (see Campbell 2004). The primary school students were identified as anxious by teacher referral, and all nine participated in the pilot. All students, in addition to the parents of the primary school students, completed preand post-measure assessments.

\section{Measures}

Spence Children's Anxiety Scale (SCAS) (Spence 1998), is a child self-report instrument that contains 44 items, 38 of which measure specific anxiety symptoms relating to social phobia, separation anxiety, panic attack/agoraphobia, obsessivecompulsive disorder, general anxiety disorder and physical injury fears. The other six items of the scale are filler items: positively worded questions on a negative scale designed to identify response acquiescence or false responses. The scale was originally designed for children from the ages of 8-12 years old, however it has also shown validity and reliability with adolescents from 12-18 years old (Muris et al. 2002; Spence 1998). Respondents are asked to indicate the frequency that each symptom occurs on a 4-point scale ranging from 'never' (scored 0) to 'always' (score 3). The SCAS has sound psychometric properties, with high internal consistency (0.92) for the total score. It has been found to exhibit reliability $(0.60)$ and high convergent validity (0.71) (Nauta et al. 2003; Spence 1998).

The Spence Children's Anxiety Scale - Parent Version (SCAS-P) contains the same 38 anxiety items as those in the SCAS, but the items are worded to gauge the parent's perspective of his/her child.

The Strengths and Difficulties Questionnaire (SDQ) (Goodman 1997), a 25item adolescent (aged 11-16 years) self-report instrument, asks about positive and negative attributes. It includes five scales: emotional symptoms, conduct problems, hyperactivity/inattention, peer relationship problems and prosocial behaviour (positive domain). Respondents are asked whether something about them is 'not true' (0), 'somewhat true' (1) or 'certainly true' (2). The first four scales can be summed to give a total difficulties score. Subscales can then be categorised into 'normal' 'borderline' and 'abnormal' to indicate risk of deviant behaviour (Goodman 1997). The SDQ has sound psychometric properties (Goodman 1997).

The Center for Epidemiologic Studies Depression Scale (CES-D) (Radloff 1977 ) is a 20 -item self-report instrument that measures the frequency of particular depressive symptoms. It contains a 4-point Likert scale that ranges from 'never' $(0)$ to 'always' (3). The total score ranges from 0 (no depressive symptoms) to 60 (many depressive symptoms). Although the CES-D was designed to measure severity of 
depressive symptoms in the general adult population, the scale has also been found to have respectable validity and reliability in the adolescent population (Radloff 1991; Roberts, Lewinsohn \& Seeley 1991).

The Revised Children's Manifest Anxiety Scale (RCMAS) (Reynolds \& Richmond 1985) is a 37-item child self-report instrument that measures physiological symptoms, worry and concentration. Respondents are asked if a statement is true (Yes) or not true about them (No). Sample items include: "I am afraid of a lot of things", "I often worry about something bad happening to me" and "I am nervous". Yes-responses are scored in the positive direction and summed to yield a total score. Scale scores are perceived to represent an individual's position on a continuum of anxiety, ranging from normal to pathogenic. The RCMAS also contains a Lie Scale that is intended to detect socially desirable responses. The scale is appropriate for use with school-aged children and adolescents between 7 and 18 years of age. The RCMAS has a high level of internal consistency, and moderate test-retest coefficients of 0.68 for total anxiety scores and 0.58 for the lie scale (Cole et al. 1998; Reynolds \& Richmond 1985).

\section{Feedback}

Attendance records were kept for all sessions, and students completed feedback sheets after the program. The parents of the primary school students were interviewed by telephone at the conclusion of the program. Teachers were asked how the children were coping in class and whether they personally were happy with the program.

\section{Procedure}

Ethical approval to conduct the research was granted by the Queensland University of Technology's Human Research Ethics Committee and consent was obtained from school principals. Written informed consent was obtained from parents of all participants, and all children gave informed assent to participate. The secondary students were identified by teacher referral and self-report as part of the school's regular screening process for early identification of mental health concerns. Secondary students completed pre- and post-measures of the SCAS, SDQ, CES-D, and RCMAS. The primary students and their parents completed pre- and postmeasures of the SCAS and SCAS-P respectively. The secondary students completed pre-measures prior to commencing the program and post-measures after they had presented the program to the primary students.

\section{Intervention}

The Worrybusters program was originally devised for primary school-aged children (5-12 years) in Australia, and is an intervention consisting of 10 one-hour sessions. It incorporates bibliotherapy, using fiction books specifically written for the program, and play therapy into a structured cognitive behaviour therapy (CBT) framework. The program provides a menu from which counsellors can select activities depending on the client's characteristics, needs and preferences (Campbell 2007). Activities include drawings, storybooks, videos, puppets, paired and group 
discussions, role-plays, balloons and breathing exercises. There are two parts to the program: teaching coping skills to deal with anxiety, and challenging participants to face their fears using the coping skills. The program uses the metaphor of going on a journey (exposure), asking children to 'pack' for the journey individual things they might need (ie. coping skills). Children are encouraged to learn from each other's role-plays and school experiences. Group processes include normalisation of anxiety experiences; group exposure through discussion and role-plays of common threatening experiences; and peer learning through discussion of successes and difficulties. Children are taught cognitive techniques to challenge unhelpful thoughts.

The program consists of ten one-hour sessions which can be delivered over a ten-week term. The sessions explore the physiology, thoughts, feelings and behaviours associated with anxiety, and provide a variety of coping strategies to manage anxiety and increase positive wellbeing (Campbell 2007).

In delivering the Worrybusters program in a cross-peer mode, the secondary students acted as the tutors. They completed the Worrybusters program with the author over ten weeks during class time in Term 2. As part of the program, the students chose the activities they believed would engage primary students. They chose picture books; made a puppet play which they videtaped; constructed flannel board stories such as "Hannah's helpful thoughts when she was competing in a carnival"; and planned construction activities to deliver to the primary students in the following term. In Term 3, they conducted the program for 1.5 hours once a week for eight weeks at the primary school with children who had been referred by a teacher, and the author. This enabled the secondary students to receive a 'double dose' of the program: first through doing the program, and then teaching it. The method of delivery is also potentially cost-effective, because a workbook is not required and only one therapist is used for the secondary and the primary students.

\section{Results}

\section{Secondary school students}

For this pilot study, differences in self-report measures were taken as an indication of the program's effectiveness for the secondary school students, as presented in Table 1. For three out of the four measures (SCAS, SDQ, and CES-D), the adolescents were less symptomatic after the interview than before. Although the sample size was quite small $(n=7)$, for SCAS the pre-post decline was approaching significance $(\mathrm{t}(6)=2.1, p=0.08)$ while the CES-D difference was statistically significant $(\mathrm{t}(6)=3.0, p<0.05)$. Among the adolescents, anxiety symptoms (as measured by the SCAS) declined six points on average, from approximately 69 to 63; and scores declined for four adolescents and remained the same for two. Depression, as measured by CES-D, declined nine points, from an approximate mean of 19 to 10 on the 20-point scale. CES-D scores declined for five students and did not change for one. On the SDQ, the average decline was just under than one point, with four students registering declines and two remaining the same. Scores on the RCMAS measure of anxiety actually increased slightly on average (three points), 
but that increase was not statistically significant. RCMAS scores did decline for two adolescents and remained the same for one more. ${ }^{1}$

Table 1. Results for secondary school students

\begin{tabular}{|c|c|c|c|c|c|c|c|c|}
\hline & $\begin{array}{l}\text { SCAS } \\
\text { pre }\end{array}$ & $\begin{array}{c}\text { SCAS } \\
\text { post }\end{array}$ & $\begin{array}{l}\text { RCMAS } \\
\text { pre }\end{array}$ & $\begin{array}{c}\text { RCMAS } \\
\text { post }\end{array}$ & $\begin{array}{l}\text { SDQ } \\
\text { pre }\end{array}$ & $\begin{array}{l}\text { SDQ } \\
\text { post }\end{array}$ & $\begin{array}{c}\text { CES- } \\
\text { D } \\
\text { pre }\end{array}$ & $\begin{array}{c}\text { CES- } \\
\text { D } \\
\text { post }\end{array}$ \\
\hline Mean & 68.6 & 62.9 & 41.4 & 44.6 & 9.0 & 8.1 & 18.6 & 9.6 \\
\hline $\begin{array}{l}\text { Stand. } \\
\text { Dev. }\end{array}$ & 17.2 & 14.0 & 7.8 & 10.0 & 2.3 & 2.4 & 10.5 & 11.0 \\
\hline Minimum & 38.0 & 38.0 & 34.0 & 31.0 & 5.0 & 5.0 & 0.0 & 0.0 \\
\hline Maximum & 97.0 & 80.0 & 56.0 & 56.0 & 12.0 & 12.0 & 32.0 & 33.0 \\
\hline $\begin{array}{l}* \text { Diff. in } \\
\text { means }\end{array}$ & \multicolumn{2}{|c|}{-5.7} & \multicolumn{2}{|c|}{3.1} & \multicolumn{2}{|c|}{-0.9} & \multicolumn{2}{|c|}{-9.0} \\
\hline $\mathrm{t}$ & \multicolumn{2}{|c|}{2.07} & \multicolumn{2}{|c|}{1.16} & \multicolumn{2}{|c|}{1.87} & \multicolumn{2}{|c|}{3.01} \\
\hline $\mathrm{df}$ & \multicolumn{2}{|l|}{6} & \multicolumn{2}{|c|}{ 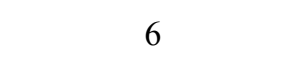 } & \multicolumn{2}{|c|}{6} & \multicolumn{2}{|c|}{6} \\
\hline sig. & \multicolumn{2}{|c|}{0.084} & \multicolumn{2}{|c|}{0.291} & \multicolumn{2}{|c|}{0.111} & \multicolumn{2}{|c|}{0.024} \\
\hline
\end{tabular}

*Difference in means is statistically significant at 0.05 level

\section{Primary school students}

The results for primary school students are shown in Table 2. Note that the statistics shown do not include the cases of those students who did complete the intervention, but who (or whose parents) did not complete the follow-up (post) anxiety instrument (SCAS). For the five students with complete data, there was a small average decline (4 points) in SCAS score. Three students had reduced anxiety scores, and for one student the reduction was considerable (from 97 to 54 on the SCAS). Two students recorded higher scores on the SCAS. This increase could be attributed to a greater awareness in these children of their anxiety symptoms, or a greater reporting of symptoms due to feeling less stigmatised or less concerned about it.

The parents of seven primary students filled out SCAS instruments before and after the intervention. These parents' evaluations of their children's anxiety showed a statistically significant decline of more than seven points over time, from an average of 69 to 62 on the SCAS scale $(\mathrm{t}(6)=3.3, p<.05)$. In all seven cases, parents recorded a decline in anxiety symptoms in their children, although in three cases it was minimal (four points or less).

\footnotetext{
${ }^{1}$ All students still reporting excessive anxiety were referred to the school counsellor.
} 
Table 2. Results for primary school students

Note: Only five students completed the post-assessment, and seven parents.

\begin{tabular}{|c|c|c|c|c|}
\hline & \multicolumn{2}{|c|}{ Student $(n=5)$} & \multicolumn{2}{|c|}{$\underline{\text { Parent }(n=7)}$} \\
\hline & SCAS pre & SCAS post & SCAS pre & SCAS post \\
\hline Mean & 67.8 & 64.0 & 69.3 & 62.0 \\
\hline Stand. Dev. & 21.2 & 10.9 & 19.6 & 19.4 \\
\hline Minimum & 43.0 & 53.0 & 48.0 & 40.0 \\
\hline Maximum & 97.0 & 78.0 & 103.0 & 99.0 \\
\hline * Diff. in means & \multicolumn{2}{|c|}{-3.8} & \multicolumn{2}{|c|}{-7.3} \\
\hline $\mathrm{t}$ & \multicolumn{2}{|c|}{0.33} & \multicolumn{2}{|c|}{3.26} \\
\hline $\mathrm{df}$ & \multicolumn{2}{|c|}{4} & \multicolumn{2}{|c|}{6} \\
\hline sig. & \multicolumn{2}{|c|}{0.757} & \multicolumn{2}{|c|}{0.017} \\
\hline
\end{tabular}

*Difference in means is statistically significant at 0.05 level

\section{Overall satisfaction with program}

Students expressed satisfaction with the program and the activities they undertook. The staff at both schools found the treatment acceptable. Parents of the primary school students reported:

She seems more confident and the teacher says she has improved. She really loved it and was so disappointed when she missed a day.

He absolutely loved doing the course and said it was really good. He told me "it's working, Mum". I can really see the difference, his fingers have stopped twitching and although he still sometimes has silly thoughts in his head it is less now. He is also less afraid of talking in front of the class.

He has good friends now and has grown in confidence.

She is not coming home in a state and not picked on anymore, seems to be better.

He has improved behaviourally and at school and said he enjoyed the program. 


\section{Discussion}

The results of this pilot study provide some preliminary evidence that cross-age peer tutoring with anxious students can reduce anxiety symptoms in some tutors and tutees. Whilst there was no significant difference between pre and post self-report measures for primary school students, parent reports indicated a significant decrease in the overall SCAS score. The high school and primary school students fully engaged with the program and reported that they enjoyed being involved. School staff members were satisfied with the program.

Measurement of anxiety is crucial to assessing the effectiveness of anxiety interventions, yet the clinical validity of many instruments currently in use is questionable. For instance, the RCMAS and SCAS may have limited sensitivity in assessing the changes between treatment conditions (Barrett, Dadds \& Rapee 1996). This issue, coupled with the limited sample size used for this study, means these measures may not be reliable or have sufficient power to detect changes from pre- to post-measures in the children and adolescent groups who participated.

It should also be noted that there was a considerable range in post-measures amongst participants. As commonly found in child anxiety research, and as observed in this study, responses with child self-report measures tend to reflect perceived social desirability (Kendall, 2006). As a result, in the current study, the levels of self-reported anxiety actually increased for some children at the post-assessment. This may be because the children felt more comfortable in disclosing fears and worries after discussing these in a group environment over the course of the intervention, and with a group facilitator who supported and encouraged them.

The results of this study indicate that a cross-age peer tutoring approach has educational benefits as it caters for different client needs, or individual children's preferences, to engage them in treatment. There is some emerging literature that client preference may influence treatment effectiveness (Lavori et al. 2001). In addition, there is evidence that matching intervention components to specific aspects of a child's anxiety problem is more effective than providing a standardised anxiety treatment package. For example, Eisen and Silverman (1998) successfully treated children suffering from generalised anxiety disorder (GAD) with cognitive response strategies where they presented with primarily cognitive features of GAD; and with somatic strategies where children presented with primarily somatic symptoms.

\section{Benefits of cross-age peer tutoring for anxious adolescents}

This study's innovative method of peer tutoring achieved its objective of engaging the anxious adolescents, with most students attending all sessions. As Chu and Kendall (2004) found, the greater a child's involvement in the therapy session, the better her/his outcome. In the present study, the adolescents reported that they liked doing the activities because they were fun and because they were not asked to fill in workbooks. The delivery method of the program also appealed to their sense of altruism in that it enabled them to help others. These older students benefited by not 
only experiencing the initial program, but also by reinforcing their understanding of the material in the process of teaching the program to others. The material also was 'one step removed' in that it was not really designed for them but for delivery to the younger children, and this assisted the adolescents to confront their fears gradually or in a less direct manner. Tutoring challenged these young people to practise their new coping skills in a situation with the potential to elicit anxiety: in the act of teaching others.

Most existing programs to reduce anxiety are designed to be brief in duration. However, excessively anxious adolescents need a relatively long time to readjust their thinking and behaviour. The original Worrybusters program comprises a standard ten sessions. However, when conducted using the peer tutoring method in this study, young people benefited from a 'double dose' of exposure to the material; first by gaining an understanding of anxiety in designing activities, and then by promoting an understanding of anxiety through engaging children in the planned activities. In effect, the older students completed the program twice. The cross-age program delivery also allowed for therapist creativity and incorporated sound educational principles into a psychological framework.

\section{Limitations}

As noted earlier, the current study was limited by several factors. It was designed to be a pilot study, comprising the first step in an evaluation of the program delivered in cross-age peer tutoring mode. Only a small number of participants were thus recruited. In light of the findings of this pilot, which showed some reduction in anxiety of students through engaging them in the Worrybusters program using a cross-peer tutoring method, the study will need to be replicated using larger numbers and including children with clinically diagnosed anxiety. Further, the results of the study discussed here should be treated with caution, as the methodological approach did not use a control group. For a larger study, a control group will also be recruited. Another limitation of the present study was the use of self-report measures rather than a clinical interview, although the participants had not been clinically assessed as anxious previously. However, as with many students with excessive anxiety symptoms, they had been identified as anxious by their teachers through classroom observation.

\section{Conclusion}

In this pilot study, the Worrybusters program was presented using a cross-peer tutoring approach. A group of secondary school students completed the program and selected the activities that they felt would appeal to primary school children. They then presented the program to the primary school group using these activities. Although limited in nature, the results of this study indicate that presenting the Worrybusters program in cross-peer mode can reduce some anxiety symptoms experienced by children and adolescents. Feedback from students and parents suggests that the students engaged with and enjoyed completing the program. Oral feedback from school staff suggests that they found the program acceptable. The next step is to further test the program using a larger group. 


\section{References}

Abidin, RR \& Robinson, LL 2002, 'Stress, biases, or professionalism: What drives teachers' referral judgments of students with challenging behaviors?', Journal of Emotional and Behavioral Disorders, vol.10, pp. 202-212.

Albano, AM, Chorpita, BE \& Barlow, DH 1996, 'Childhood anxiety disorders', in Child psychopathology, eds EJ Mash \& RA Barkley, Guilford Press, New York, pp. 196-244.

Asher, SR \& Coie, JD (eds) 1990, Peer rejection in childhood, Cambridge University Press, New York.

Barnes, J 1998, 'Mental health promotion: a developmental perspective', Psychology, Health \& Medicine, vol. 3, pp. 55-69.

Barrett, PM, Dadds, MR \& Rapee, RM 1996, 'Family treatment of childhood anxiety: a controlled clinical trial', Journal of Consulting and Clinical Psychology, vol. 64, pp. 333-342.

Barrett, P \& Turner, C 2001, 'Prevention of anxiety symptoms in primary school children: Preliminary results from a universal school-based trial', British Journal of Clinical Psychology, vol. 40, pp. 399-410.

Burke, JD, Burke, KC \& Rae, DS 1994, 'Increased rates of drug abuse and dependence after onset of mood or anxiety disorders in adolescence', Hospital and Community Psychiatry, vol. 45, pp. 451-455.

Campbell, M 2004, 'Identification of "at-risk" students for prevention and early intervention programs in secondary schools', Australian Journal of Guidance and Counselling, vol. 14, pp. 65-77.

Campbell, M 2007, The Worrybusters program for anxious children. Unpublished manuscript, Queensland University of Technology.

Cantwell, DP, Lewinsohn, PM, Rohde, P \& Seeley, JR 1997, 'Correspondence between adolescent report and parent report of psychiatric diagnostic data', Journal of the American Academy of Child \& Adolescent Psychiatry, vol. 36, pp. 610-619.

Carlton, PA \& Deane, FP 2000, 'Impact of attitudes and suicidal ideation on adolescents' interventions to seek professional psychological help', Journal of Adolescence, vol. 23, pp. 35-45.

Chu, BC \& Kendall, PC 2004, 'Positive association of child involvement and treatment outcome within a manual-based cognitive-behavioral treatment for children with anxiety', Journal of Consulting and Clinical Psychology, vol. 72, pp. 821-829. 
Ciarrochi, J, Wilson, CJ, Deane, FP \& Rickwood, D 2003, 'Do difficult emotions inhibit help-seeking in adolescence? The role of age and emotional competence in predicting help-seeking intentions', Counselling Psychology Quarterly, vol. 16, pp. 103-121.

Cole, DA, Peeke, IG, Martin, JM, Truglio, R \& Senczynski, AD 1998, 'A longitudinal look at the relation between depression and anxiety in children and adolescents', Journal of Consulting and Clinical Psychology, vol. 66, pp. 451-460.

Costello, EJ \& Angold, A 1995, 'Epidemiology', in Anxiety disorders in children and adolescents, ed. JS March, Guilford Press, New York, pp. 109-124.

Dadds, M, Holland, D, Laurens, K, Mullins, M, Barrett, P \& Spence, S 1999, 'Early intervention and prevention of anxiety disorders in children: Results at 2Year follow-up', Journal of Continuing and Clinical Psychology, vol. 67, no. 1, pp. 145-150.

Davis, C, Martin, G, Kosky, R \& O'Hanlon, A 2000, 'Early intervention in the mental health of young people: a literature review', The Australian Early Intervention Network for Mental Health in Young People, Australia.

Deane, FP, Wilson, CJ \& Ciarrochi, J 2001, 'Suicidal ideation and help-negation: Not just hopelessness or prior help', Journal of Clinical Psychology, vol. 57, pp. 1-14.

Deas-Nesmith, D, Brady, KT \& Campbell, S 1998, 'Comorbid substance use and anxiety disorders in adolescents', Journal of Psychopathology \& Behavioral Assessment, vol. 20, pp. 139-148.

Dobson, KS 1985, 'The relationship between anxiety and depression', Clinical Psychology Review, vol. 5, pp. 307-324.

Donovan, CL \& Spence, SH 2000, 'Prevention of childhood anxiety disorders', Clinical Psychology Review, vol. 20, pp. 509-531.

Eisen, AR \& Silverman, WK 1998, 'Prescriptive treatment for generalised anxiety disorder in children', Behavior Therapy, vol. 29, pp. 105-121.

Ellis, LA, Marsh, HW, Craven, RG \& Richards, GE 2003, 'Peers helping peers: the effectiveness of a peer support program in enhancing self-concept and other desirable outcomes', paper presented at the NZARE Australian Association for Research in Education, Auckland, New Zealand.

Farrell, LJ, Barrett, PM \& Claassens, S 2005, 'Community trial of an evidencebased anxiety intervention for children and adolescents (the FRIENDS program): a pilot study', Behaviour Change, vol. 22, pp. 236-248. 
Frydenberg, E \& Lewis, R 2000, 'Teaching coping to adolescents: When and to whom?', American Educational Research Journal, vol. 37, pp. 727-745.

Gardiner, J 1994, 'Differential teacher response to type of behavioural disturbance: the good, the bad and the forgotten', paper presented at the Australian Association for Research in Education Conference, University of Newcastle.

Gaustad, J 1993, 'Peer and cross-age tutoring', Emergency Librarian, vol. 21, pp. 34-36.

Gensemer, P 2000, 'Effectiveness of cross-age and peer mentoring', Information Analyses, vol. 30, pp. 1-15.

Godart, NT, Flament, MF, Lecrubier, Y \& Jeammet, P 2000, 'Anxiety disorders in anorexia nervosa and bulimia nervosa: Comorbidity and chronology of appearance', European Psychiatry, vol. 15, pp. 38-45.

Goodman, R 1997, 'The Strengths and Difficulties Questionnaire: a research note', Journal of Child Psychology and Psychiatry, vol. 38, pp. 581-586.

Green, MT, Clopton, JR \& Pope, AW 1996, 'Understanding gender differences in referral of children to mental health services', Journal of Emotional and Behavioral Disorders, vol. 4, pp. 182-190.

Hibbert, A, Fogelman, K \& Manor, O 1990, 'Occupational outcomes of Truancy', British Journal of Educational Psychology, vol. 60, pp. 171-179.

Ialongo, N, Edlesohn, G, Werthamer-Larsson, I, Crockett, I \& Kellam, S 1994, 'The significance of self-reported anxious symptoms in first grade children', Journal of Abnormal Child Psychology, vol. 22, pp. 441-455.

Ialongo, N, Edlesohn, G, Werthamer-Larsson, I, Crockett, I \& Kellam, S 1995, 'The significance of self-reported anxious symptoms in first grade children: Prediction to anxious symptoms and adaptive functioning in fifth grade', Journal of Child Psychology and Psychiatry, vol. 36, pp. 427-437.

Jacobson, J, Thrope, L, Fisher, D, Lapp, D, Frey, N \& Flood, J 2001, 'Cross-age tutoring: a literacy improvement approach for struggling adolescent readers', Journal of Adolescent \& Adult Literacy, vol. 44, pp. 528-536.

Jorm, AF 2000, 'Mental health literacy: Public knowledge and beliefs about mental disorders', British Journal of Psychiatry, vol. 177, pp. 396-401.

Juel, C 1991, 'Cross-age tutoring between student athletes and at-risk children', The Reading Teacher, vol. 45, pp. 178-186.

Kashani, JH \& Orvaschel, H 1990, ‘A community study of anxiety in 
children and adolescents', American Journal of Psychology, vol. 147, pp. 313-318.

Kazdin, AE \& Weisz, JR 1998, 'Identifying and developing empirically supported child and adolescent treatments', Journal of Consulting and Clinical Psychology, vol. 66, pp. 19-36.

Kendall, PC (ed.) 2006, Child and adolescent therapy: Cognitive-behavioural procedures, 3rd edn, Guilford Press, New York.

Kovacs, M, \& Devlin, B 1998, 'Internalizing disorders in childhood', Journal of Child Psychology and Psychiatry, vol. 39, pp. 17-63.

Kraemer, HC, Measelle, JR, Ablow, JC, Essex, MJ, Boyce, WT \& Kupfer, DJ 2003, 'A new approach to integrating data from multiple informants in psychiatric assessment and research: Mixing and matching contexts and perspectives', American Journal of Psychiatry, vol. 160, pp. 1566-1577.

Lavori, PW, Rush, AJ, Wisniewski, SR, Alpert, J, Fava, M, Kupfer, DJ, Nierenberg, A, Quitkin, FM, Sackeim, HA, Thase, ME \& Trivedi, M 2001, 'Strengthening clinical effectiveness trials: Equipoise-stratified randomization', Biological Psychiatry, vol. 50, pp. 792-801.

McBride, N, Midford, R \& James, R 1995, 'Structural and management changes that encourage schools to adopt comprehensive health promotion programs', Health Promotion Journal of Australia, vol. 5, pp. 17-23.

McKinstery, J \& Topping, KJ 2003, 'Cross-age peer tutoring of thinking skills in the high school', Educational Psychology in Practice, vol. 19, pp. 199-217.

Martin, A \& Cohen, DJ 2000, "Adolescent depression: Window of "missed" opportunity’, American Journal of Psychiatry, vol. 157, pp. 1549-1551.

Mattison, RE 1988, 'Suicide and other consequences of childhood and adolescent anxiety disorders', Journal of Clinical Psychiatry, vol. 49, pp. 9-11.

Messer, SC \& Beidel, DC 1994, 'Psychosocial correlates of childhood anxiety disorders', Journal of the American Academy of Child and Adolescent Psychiatry, vol. 33, pp. 975-983.

Miller, L 2008, 'Facing fears: the feasibility of anxiety universal prevention efforts with children and adolescents', Cognitive and Behavioral Practice, vol. 15, no. 1 , pp. 28-35.

Miller, SR \& Miller, PF 1995, 'Cross-age peer tutoring. A strategy for promoting self-determination in students with severe emotional disabilities/behavior disorders', Preventing School Failure, vol. 39, pp. 32-38. 
Muris, P, Merckelbach, H, Ollendick, T, King, N \& Bogie, N 2002, 'Three traditional and three new childhood anxiety questionnaires: Their reliability and validity in a normal adolescent sample', Behaviour Research and Therapy, vol. 40, pp. 753-772.

Nauta, MH, Scholing, A, Emmelkamp, PMG \& Minderaa, RB 2003, 'Cognitivebehavioural therapy for children with anxiety disorders in a clinical setting: No additional effect of cognitive parent training', Journal of the American Academy of Child and Adolescent Psychiatry, vol. 42, no. 11, pp. 1270-1278.

Noll, V 1997, 'Cross-age mentoring program for social skills development', School Counselor, vol. 44, pp. 239-242.

Nugent, M 2001, 'Raising reading standards - the Reading Partners approach: Cross-age peer tutoring in a special school', British Journal of Special Education, vol. 28, no. 2, pp. 71-79.

Pearcy, MT, Clopton, JR \& Pope, AW 1993, 'Influences on teacher referral of children to mental health services: Gender, severity, and internalizing versus externalising problems', Journal of Emotional and Behavioral Disorders, vol. 1, pp. 165-169.

Potter, J 1997, 'New directions in student tutoring', Education and Training, vol. 39, no. 1, pp. 24-29.

Radloff, LS 1977, 'The CES-D scale: a self-report depression scale for research in the general population', Applied Psychological Measurement, vol. 1, pp. $385-401$.

Radloff, LS 1991, 'The use of the Center for Epidemiologic Studies Depression Scale in adolescents and young adults', Journal of Youth and Adolescence, vol. 20, pp. 149-166.

Reinherz, HZ, Paradis, AD, Giacomia, RM, Stashwick, CK \& Fitzmaurice, G 2003, 'Childhood and adolescent predictors of major depression in the transition to adulthood', American Journal of Psychiatry, vol. 160, pp. 2141-2147.

Reynolds, CR 1980, 'Concurrent validity of What I Think and Feel: the Revised Children's Manifest Anxiety Scale', Journal of Consulting and Clinical Psychology, vol. 48, pp. 774-775.

Reynolds, CR 1981, 'Long-term stability of scores on the Revised Children's Manifest Anxiety Scale', Perception and Motor Skills, vol. 53, p. 702.

Reynolds, CR \& Richmond, BO 1985, Revised Children Manifest Anxiety Scale: Manual, Western Psychological Services, Los Angeles. 
Rhode, P, Lewinsohn, PM \& Selby, JR 1996, 'Psychiatric comorbidity with problematic alcohol use in high school students', Journal of the American Academy of Child and Adolescent Psychiatry, vol. 35, pp. 101-109.

Rickwood, DJ 1995, 'The effectiveness of seeking help for coping with personal problems in late adolescence', Journal of Youth and Adolescence, vol. 24, pp. $685-703$.

Roberts, RE, Lewinsohn, PM \& Seeley, JR 1991, 'Screening for adolescent depression: a comparison of depression scales'. Journal of the American Academy of Child and Adolescent Psychiatry, vol. 30, pp. 58-66.

Sawyer, MG, Arney, FM, Baghurst, PA, Clark, JJ, Graetz, BW, Kosky, RJ, Nurcombe, B, Patton, GC, Prior, MR, Raphael, B, Rey, J, Whaites, LC, Zubrick, SR 2000, Mental health of young people in Australia: Child and adolescent component of the national survey of mental health and well-being, Commonwealth Department of Health and Aged Care, Canberra.

Spence, SH 1998, 'A measure of anxiety symptoms in children', Behaviour Research and Therapy, vol. 36, pp. 545-566.

Strauss, CC, Frame, CL \& Forehand, RL 1987, 'Psychosocial impairment associated with anxiety in children', Journal of Clinical Child Psychology, vol .16, pp. 235-239.

Tomb, M \& Hunter, L 2004, 'Prevention of anxiety in children and adolescents in a school-setting: the role of school-based practitioners', Children and Schools, vol. 26 , no. 1 , pp. $87-101$.

Verhulst, FC, van der Ende, J, Ferdinand, RF \& Kasius, MC 1997, 'The prevalence of DSM-III-R diagnoses in national sample of Dutch adolescents', Archives of General Psychiatry, vol. 54, pp. 329-336.

Wilson, CJ \& Deane, FP 2001, 'Adolescent opinions about reducing help-seeking barriers and increasing appropriate help engagement', Journal of Educational and Psychological Consultation, vol. 12, pp. 345-364. 